\title{
Quality of life in breast cancer survivors
}

\author{
Weruska Alcoforado Costa $^{1}$, José Eleutério Jr. ${ }^{2}$, Paulo César Giraldo ${ }^{3}$, Ana Katherine Gonçalves ${ }^{1 *}$ \\ 'Universidade Federal do Rio Grande do Norte (UFRN), Natal, RN, Brazil \\ ${ }^{2}$ Universidade Federal do Ceará (UFC), Fortaleza, CE, Brazil \\ 3Universidade Estadual de Campinas (Unicamp), Campinas, SP, Brazil
}

Study conducted at Universidade Federal do Rio Grande do Norte (UFRN), Natal, RN, Brazil

Article received: $12 / 18 / 2016$ Accepted for publication: $1 / 2 / 2017$

*Correspondence: Address: Rua Major Laurentino de Morais, 1.218/1.301

Natal, RN - Brazil Postal code: $59020-390$ anakatherine@ufrnet.br

http://dx.doi.org/10.1590/1806-9282.63.07.583

\section{SUMMARY}

Objective: To evaluate the influence of functional capacity (FC) and how it affects quality of life (QoL) in breast cancer survivors.

Method: A total of 400 breast cancer survivors were studied - 118 without metastasis, 160 with locoregional metastasis and 122 with distant metastasis. The European Organization for Research and Treatment for Cancer Quality of Life Questionnaire-Core 30 (EORTC QLQ-C30), Breast Cancer-Specific (EORTC QLQ-BR23), and the Karnofsky Performance Scale (KPS) were used to evaluate FC and QoL.

Results: Women with distant metastases presented lower KPS 75.3 (SD=12.5) ( $\mathrm{p}<0.001)$. For QLQ-C30, the mean of the Functional Scale for patients with distant metastasis was $57(\mathrm{SD}=19)(\mathrm{p}<0.001)$, and the mean of the Symptom Scale for patients with distant metastasis was $37(\mathrm{SD}=20)(\mathrm{p}<0.001)$. Both the scales for pain and fatigue showed the highest mean in the groups. For the Global Health Scale, patients without metastasis scored a mean of $62(S D=24)$ points, while those with locoregional metastases scored a mean of $63(\mathrm{SD}=21.4)$, and distant metastasis scored $51.3(\mathrm{SD}=24)$ points. In the group with distant metastases, $105(87 \%)$ had pain, and the average KPS was $74(\mathrm{SD}=12.0)(\mathrm{p}=0.001)$.

Conclusion: Breast cancer was associated with decreased FC, compromised QoL in women with locoregional and distant metastases compared to those without metastasis.

Keywords: survivors, breast neoplasms, quality of life, functional capacity.

\section{INTRODUCTION}

Breast cancer is the most prevalent type of cancer among women throughout the world and is considered the most commonly diagnosed type of cancer. However, due to new technologies and treatments, the number of women living with the disease increases every year, which explains the growing interest in quality of life (QoL) of breast cancer patients. ${ }^{1-5}$

The number of breast cancer survivors is increasing around the world; thus, it is important to improve the health-related QoL of this population. Ability to perform daily activities, patient satisfaction and levels of functionality are all essential to determining QoL in breast cancer survivors. Persistent symptoms associated with the adverse effects of treatment, such as pain and fatigue, can interfere with functional capacity (FC) and directly affect QoL, and consequently should not be left untreated. ${ }^{5-10}$

Decreased FC may affect the QoL of patients, especially those with advanced cancer. This is important be- cause $38 \%$ of the women diagnosed annually already have advanced cancer. $^{6}$

FC and autonomy are some of the most important indicators of health in cancer patients. The current understanding of FC is quite holistic in that it includes not only areas of physical performance, such as muscular strength, cardiopulmonary endurance and range of motion, but also the emotional and psychological state as well as environmental and social circumstances. ${ }^{11-16}$

According to the World Health Organization's International Classification of Functioning, Disability and Health (ICF), function is defined as the interactions between an individual, their health condition and the social and personal context in which they live. ${ }^{16-18}$ It is the complex interaction between these factors that determines function and impairment. In the context of breast cancer, morbidity associated with the disease and its treatments can lead to impairments in physiological, psychological or behavioral attributes (body functions and structures), 
eventually leading to limitations in the ability to execute daily activities and participate in social events. ${ }^{16}$

Considering the aspects above, $\mathrm{FC}$ is not only a marker of health-related QoL in breast cancer survivors but also a key aspect in the development of rehabilitation techniques. These techniques are used to improve function in breast cancer survivors and identify functional limitations that help to make decisions concerning treatment and rehabilitation. ${ }^{16}$

Functional limitations may have a significant impact on QoL, but less is known about the impact of other variables such as age, presence of metastasis and pain on functional limitation in breast cancer survivors. This study aimed to assess the influence of pain, metastasis and sociodemographic variables on functional performance and QoL of breast cancer survivors.

\section{Method}

The sample was comprised of a total of 400 breast cancer survivors in different disease stages at the time of diagnosis: S0=5 (1.25\%), SI=113 (28.25\%), SIIA=4 (1\%), SIIB=20 (5\%), SIIIA=66 (16.5\%), SIIIB=63 (15.75\%), SIIIC=7 (1.75\%) and $\mathrm{IV}=122(30.5 \%)$, undergoing chemotherapy, radiotherapy, surgery or hormone therapy, or exclusively palliative care. Three study groups were identified in the sample: 118 patients without metastasized breast cancer, 160 with locoregional metastases and 122 with distant metastases. The research took place in the oncology centre at a referral hospital in a medium-sized city in the northeast of Brazil from July 2014 to April 2015.

Patients were selected by means of non-probability sampling, and patient interviews were conducted during medical consultations.

Patients eligible for the study had been diagnosed with breast cancer, were undergoing treatment and/or palliative care, and were over 18 years of age. Women without cognitive ability or speech, as well as patients without previous treatment, and those previously diagnosed with depression were excluded.

Ethical issues were considered, and the local Research Ethics Committee approved the present study (no. CAAE 17956113.9.0000.5293) in compliance with the Declaration of Helsinki and Resolution 466/12 of the Brazilian National Health Council, which addresses research on human beings. Before starting the interview, the researcher explained the study objectives and requested a free and informed consent ensuring that participation was voluntary and that answers would be anonymous and confidential.

Sociodemographic data including age, place of origin, education, marital status, occupation, religion, clinical data, metastasis, type of treatment, and pain symptoms were obtained from the patients and patient records.

The functionality of the breast cancer survivors was assessed using the Karnofsky Performance Scale (KPS). KPS measures functionality, with scores ranging from 0 (which indicates the death of the patient) to 100 (patient performs their daily activities normally). ${ }^{19,20}$

To assess QoL, the European Organization for Research and Treatment for Cancer Quality of Life Questionnaire-Core 30 (EORTC QLQ-C30) was used. The questionnaire is valid and reliable for assessing QoL of cancer survivors, and thus it is considered useful in many clinical trials and research. The EORTC QLQ-C30 (version 3.0) is composed of three scales, corresponding to the patient's condition in the prior week. The first is the Global Health Scale. The second is the Functional Scale, consisting of five domains: physical, emotional, social, cognitive and role-playing. The third, the Symptom Scale, consists of three domains (pain, fatigue, nausea and vomiting) and six single items (dyspnea, sleep disorders, loss of appetite, constipation, diarrhea, and financial difficulties). ${ }^{13,21}$ Questions $01-28$ contained in the instrument are arranged in a four-point Likert scale, where the respondents classified each item with responses ranging from strongly disagree (1 point) to strongly agree (4 points). Questions 29 and 30, in turn, also used the Likert scale, but with answers ranging from 1 to 7 points, classified as unsatisfactory to satisfactory, respectively. All items are linearly transformed into scales ranging from 0 to 100 . In the case of the Functional Scale and Global Health Scale, higher scores indicate a higher level of functioning or overall QoL. On the other hand, for the Symptom Scale and single items, higher scores imply a higher level of symptoms or problems. ${ }^{21}$

The QLQ-BR23 module, created specifically for breast cancer survivors, has been translated and validated in Portuguese. It consists of 23 questions, using a Likert scale with the mismatch response to the lower value of 1 , and the highest value of 4 . This module is divided into two scales, one of which is a Functional Scale that includes four items on body image, two on sexual function, one on sexual pleasure, and one on future prospects. The other scale is the Symptom Scale, which includes seven items on systemic therapy, four on symptoms of breast cancer, three on symptoms of the arm, and one on hair loss. ${ }^{21}$

Authorization for the use of these instruments was requested via e-mail with the EORTC group, and a copy of the questionnaire and manual were presented for data analysis.

\section{Statistical treatment}

Initially, a descriptive analysis of qualitative variables was performed through the distribution of absolute and 
relative frequencies. For the quantitative variables (sociodemographics such as age, clinical such as KPS, and the instrument variables EORTC QLQ-C30 and QLQ-BR23), measures of central tendency and dispersion (mean and standard deviation) were used. Then, analysis of variance (ANOVA) was performed to verify any relation among KPS, Symptom Scale, Functional Scale, and Global Health Scale of the EORTC QLQ-C30, as well as scales of symptoms and functional QLQ-BR23 with patients without metastases and with the presence of locoregional or distant metastases. It was concluded by ANOVA that there was a significant difference between women with and without metastases. Tukey test, a multiple comparison test, was used to evaluate the magnitude of these differences. Student's t-test was used to determine any correlation between KPS (FC) and pain. To investigate the relations among the EORTC instrument variables according to KPS, we used the Pearson correlation, which is a parametric correlation. The study used a significance level of $5 \%$, and all the calculations were performed with SPSS.V.13.

\section{RESULTS}

As shown in Table 1, lower FC (KPS) was observed in women with metastasis $(\mathrm{p}<0.001)$. The mean score of patients without metastasis was 90.5 points $(\mathrm{SD}=9.7)$, with locoregional metastasis scoring $87.5(\mathrm{SD}=8.8)$ and distant metastasis scoring 75.3 ( $\mathrm{SD}=12.5)$. Differences in FC were detected in the comparison between groups regarding metastases: without and locoregional $(\mathrm{p}=0.045)$, without and distant $(\mathrm{p}<0.001)$, locoregional and distant metastases $(\mathrm{p}<0.001)$. As for Functional Scale and Global Health EORTC QLQ-C30, there were also differences among the groups $(p<0.001)$. Concerning the Symptom Scale (EORTC QLQ-C30), variations were observed between the following groups: without and with distant metastases $(\mathrm{p}=0.001)$; with locoregional and distant metastases $(\mathrm{p}<0.001)$. Regarding the Symptom and Functional Scales (EORTC QLQ-BR23), differences were also detected between women with locoregional and women with distant metastasis $(\mathrm{p}<0.001)$.

In Table 2, correlating pain and FC with the presence of metastases, it was identified that the total sample, 287 (71.75\%) patients, had pain and an average KPS of $82.2 \%$ $(\mathrm{SD}=12.3), \mathrm{p}<0.001$. For women with distant metastases, $105(87 \%)$ complained of pain and the average KPS was $74 \%$ ( $\mathrm{SD}=12.0), \mathrm{p}=0.001$ (Table 2).

In Table 3, FC (KPS) was closely related to QoL by EORTC QLQ-C30, mainly in the following scales: Functional Scale, Symptom Scale and Global Health Scale in women without, with locoregional and distant metastases $(\mathrm{p}<0.001)$.

\section{Discussion}

It is usual for breast cancer survivors to suffer from persistent arm morbidity (i.e., pain, limited range of motion, reduced strength) with decreased upper limb function after surgery and/or adjuvant treatment. ${ }^{16}$ This study found a significant relation between metastases (locoregional and distant) and decrease of FC, which in turn affects QoL. This result is generally observed when women with distant metastases are compared to women without metastasis. The presence of distant metastases seems to decrease FC in patients, limiting daily activities and consequently reducing QoL of breast cancer survivors. Such reduced functionality can lead to physical inactivity, and contribute to worsening of the health status in breast cancer survivors. ${ }^{16,22}$

Additionally, pain and FC affect the performance status, a factor decisive in the decision to undergo therapy or palliative care alone. Thus, patients with good FC (KPS ranging from 60 to $90 \%$ ) are presumed strong enough to receive any treatment, which is considered the standard to participate in clinical trial studies. ${ }^{23,24}$ This study found that even patients with a KPS of $40 \%$ received some type of treatment despite the patient's lower FC and increased propensity to poorer QoL.,

Therefore, quantification of physical function is becoming an important element in the verification of health-related QoL, considering that cancer is often associated with decreased physical capacity, which interferes with daily activities, especially for those with metastases. ${ }^{23-25}$ Most patients in our study had metastases, mainly locoregional, which is similar to findings by Montazeri et al. ${ }^{25}$ that patients with advanced cancer may have poorer QoL. ${ }^{78,13}$ Zimmerman et al. ${ }^{26}$ also confirmed performance status to be an important determinant of QoL in advanced cancer.

Pain is very frequent in cancer patients. In our study, breast cancer survivors with metastases suffered from more pain than those without metastasis. Pain was correlated to decreased FC, compromising the QoL of these women. ${ }^{16}$

QoL also has been considered an important predictor of prognosis for cancer patients. ${ }^{27,28}$ The assessment of QoL can determine the impact of disease and treatment in patients. ${ }^{29}$ We used EORTC QLQ-C30 and EORTC QLQ-BR23 to assess $\mathrm{QoL}$, and observed a positive correlation between FC and QoL. Evaluating all domains, women without metastasis showed better QoL (EORTC) and FC (KPS) than those with locoregional and distant metastases.

In this study, we found that breast cancer was associated with decreased FC, compromising QoL in women 
TABLE 1 Quality of life and functional capacity relating to metastases.

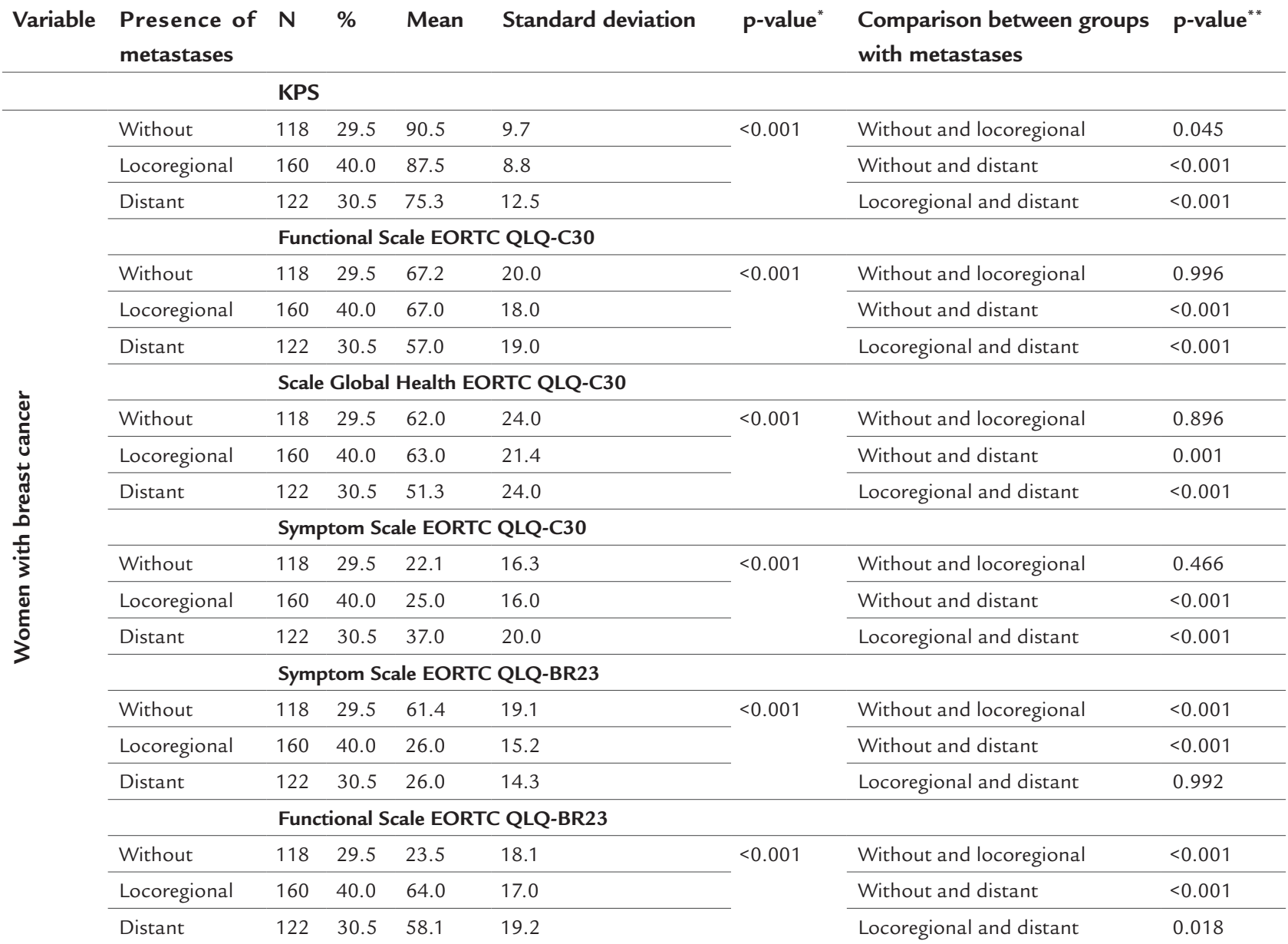

*Analysis of variance (ANOVA)

**Multiple Comparison Test (Turkey)

Significance level of $5 \%$.

\section{TABLE 2 Correlation between pain and functional capacity and the presence of metastases.}

\begin{tabular}{|c|c|c|c|c|c|c|c|}
\hline Variable & $\mathbf{N}$ & $\%$ & Mean & Standard deviation & Minimum & Maximum & p-value* \\
\hline Pain & & & KPS & & & & \\
\hline \multicolumn{8}{|c|}{ Without metastasis } \\
\hline No & 51 & 43.0 & 93.9 & 7.5 & 70.0 & 100.0 & \multirow[t]{2}{*}{0.001} \\
\hline Yes & 67 & 57.0 & 87.9 & 10.7 & 50.0 & 100.0 & \\
\hline \multicolumn{8}{|c|}{ Locoregional metastases } \\
\hline No & 45 & 28.0 & 90.0 & 8.8 & 60.0 & 100.0 & \multirow[t]{2}{*}{0.065} \\
\hline Yes & 115 & 72.0 & 87.0 & 8.7 & 60.0 & 100.0 & \\
\hline \multicolumn{8}{|c|}{ Distant metastases } \\
\hline No & 17 & 14.0 & 85.0 & 11.2 & 50.0 & 100.0 & \multirow[t]{2}{*}{0.001} \\
\hline Yes & 105 & 87.0 & 74.0 & 12.0 & 40.0 & 90.0 & \\
\hline \multicolumn{8}{|l|}{ Total } \\
\hline No & 113 & 28.3 & 90.8 & 9.2 & 50.0 & 100.0 & \multirow[t]{2}{*}{0.001} \\
\hline Yes & 287 & 71.7 & 82.2 & 12.3 & 40.0 & 100.0 & \\
\hline
\end{tabular}

*Analysis of variance (ANOVA)

Significance level $5 \%$. 
TABLE 3 Correlation between functional capacity and quality of life according to the EORTC QLQ-C30 and BR23 in women with breast cancer metastases.

\begin{tabular}{|c|c|c|c|c|}
\hline \multirow[t]{2}{*}{ Breast cancer survivors } & \multirow[t]{2}{*}{ EORTC } & \multicolumn{3}{|l|}{ KPS } \\
\hline & & Correlation & Type & p-value ${ }^{* * *}$ \\
\hline \multirow[t]{5}{*}{ Without metastasis } & Functional Scale* & 0.57 & Accented & $<0.001$ \\
\hline & Symptom Scale* & -0.54 & Accented & $<0.001$ \\
\hline & Global Health Scale* & 0.52 & Accented & $<0.001$ \\
\hline & Functional Scale** & -0.43 & Appreciable & $<0.001$ \\
\hline & Symptom Scale** & -0.28 & Low & 0.002 \\
\hline \multirow[t]{5}{*}{ Locoregional metastases } & Functional Scale* & 0.57 & Accented & $<0.001$ \\
\hline & Symptom Scale* & 0.53 & Accented & $<0.001$ \\
\hline & Global Health Scale* & 0.51 & Accented & $<0.001$ \\
\hline & Functional Scale** & -0.22 & Low & 0.005 \\
\hline & Symptom Scale** & -0.30 & Appreciable & $<0.001$ \\
\hline \multirow[t]{5}{*}{ Distant metastases } & Functional Scale* & 0.70 & Accented & $<0.001$ \\
\hline & Symptom Scale* & -0.63 & Accented & $<0.001$ \\
\hline & Global Health Scale* & 0.70 & Accented & $<0.001$ \\
\hline & Functional Scale** & 0.17 & Low & 0.070 \\
\hline & Symptom Scale ${ }^{* *}$ & 0.41 & Appreciable & $<0.001$ \\
\hline
\end{tabular}

*EORTC QLQ-C30

**EORTC QLQ-BR23.

*** Spearman test.

with locoregional and distant metastases compared to those without metastasis. Probably, functional limitations and physical inactivity are linked to worse QoL.

Recently, high FC has been associated with survival in breast cancer survivors. In a large, prospective population-based cohort of early-stage breast cancer survivors, the Life After Cancer Epidemiology (LACE) cohort, participants were asked if they could accomplish a list of daily activities. ${ }^{30}$ At least one functional impairment existed in $39 \%$ of breast cancer survivors at the median follow-up time of nine years post-diagnosis, irrespective of clinical, lifestyle and sociodemographic factors. ${ }^{30}$ Survivors who were older, less educated and obese had a higher risk of having greater functional limitation. Women with functional limitations were less physically active compared with those without impairment. ${ }^{30}$ Functional limitations were linked to a significantly increased mortality from all causes. This is not a new finding, since it is known that, for women in the general population, physical inactivity is a strong predictor of mortality. ${ }^{31,32}$

Functional limitations impact the QoL of breast cancer survivors. Breast cancer care needs to integrate important information on patient FC by means of self-report, consequently adjusting the treatment accordingly. This is essential in order to fully understand the multiple func- tional limitations associated with breast cancer and to improve rehabilitation care for breast cancer survivors.

Breast cancer affects different aspects of QoL for thousands of women around the world. ${ }^{33}$ From the time of diagnosis, the initial stages of treatment and the months following treatment completion are difficult times for patients and relatives. During these times, breast cancer patients can easily suffer from poor adjustment and decreased QoL. As a result, it is critical for health care professionals to become familiar with the impact of a breast cancer diagnosis and its treatment on patient QoL.

\section{Conflict of Interest}

The authors declare no conflict of interest.

\section{Resumo}

Qualidade de vida em sobreviventes do câncer de mama

Objetivo: Avaliar a influência da capacidade funcional (CF) sobre a qualidade de vida (QV) de mulheres sobreviventes de câncer de mama.

Método: 400 mulheres sobreviventes de câncer de mama foram avaliadas -118 sem metástases, 160 com metástases locorregionais e 122 com metástases a distância. Para avaliar a capacidade funcional e a qualidade de vida, os 
seguintes instrumentos foram utilizados: European Organization for Research and Treatment for Cancer Quality of Life Questionnaire-Core 30 (EORTC QLQ-C30), Breast Cancer-Specific (EORTC QLQ-BR23) e Karnofsky Performance Scale (KPS).

Resultados: Mulheres com metástases a distância apresentaram menor KPS 75,3 ( $D P=12,5)(\mathrm{p}<0,001)$. Quanto ao QLQ-C30, a média da escala funcional para pacientes com metástases a distância foi de $57(\mathrm{DP}=19)(\mathrm{p}<0,001)$. A média da escala de sintomas das pacientes com metástase a distância foi de $37(\mathrm{DP}=20)(\mathrm{p}<0,001)$. A escala de dor e fadiga apresentou a maior média nos grupos. Em relação à Escala Global de Saúde, as pacientes sem metástase tinham uma média de $62(\mathrm{DP}=24)$; com metástase locorregional, 63 ( $\mathrm{DP}=21,4)$; e com metástase a distância, 51,3 (DP=24). Para o grupo com metástase a distância, 105 (87\%) tiveram dor, e a média do KPS foi de $74(\mathrm{DP}=2,0)(\mathrm{p}=0,001)$.

Conclusão: $O$ câncer de mama foi associado com diminuição da capacidade funcional, comprometendo a qualidade de vida das mulheres sobreviventes do câncer de mama com metástases locorregional ou a distância, quando comparadas àquelas sem metástases.

Palavras-chave: sobreviventes, neoplasias da mama, qualidade de vida, capacidade funcional.

\section{REFERENCES}

1. Jemal A, Bray F, Center MM, Ferlay J, Ward E, Forman D. Global cancer statistics. CA Cancer J Clin 2011; 61(2):69-90.

2. Abrahams HJ, Gielissen MF, Goedendorp MM, Berends T, Peters ME, Poort $\mathrm{H}$, et al. A randomized controlled trial of web-based cognitive behavioral therapy for severely fatigued breast cancer survivors (CHANGE-study): study protocol. BMC Cancer. 2015; 15:765.

3. Manandhar S, Shrestha DS, Taechaboonsermsk P, Siri S, Suparp J. Quality of life among breast cancer patients undergoing treatment in National Cancer Centers in Nepal. Asian Pac J Cancer Prev. 2014; 15(22):9753-7.

4. Li L, Zhu X, Yang Y, He J, Yi J, Wang Y, et al. Cognitive emotion regulation: caracteristics and effect on quality of life in women with breast cancer. Health Qual Life Outcomes. 2015; 13:51.

5. Wurz A, Aubin A, Brunet J. Breast cancer survivorsivorsvorsvorsorsancer. tre participating in a group-based physical activity program offered in the community. Support Care Cancer. 2015; 23(8):2407-16.

6. Wyatt G, Sikorskii A, Rahbar M, Victorson D, You M. Health-related quality of life outcomes: a reflexology trial with patients with advanced-stage breast cancer. Oncol Nurs Forum. 2012; 39(6):568-77.

7. Cheville AL, Troxel AB, Basford JR, Kornblith AB. Prevalence and treatment patterns of physical impairments in patients with metastatic breast cancer. J Clin Oncol. 2008; 26(16):2621-9.

8. Hau E, Browne L, Capp A, Delaney GP, Fox C, Kearsley JH, et al. The impact of breast cosmetic and functional outcomes on quality of life: long-term results from the St. George and Wollongong randomized breast boost trial. Breast Cancer Res Treat. 2013; 139(1):115-23.
9. Cramarossa G, Chow E, Zhang L, Bedard G, Zeng L, Sahgal A, et al. Predictive factors for overall quality of life in patients with advanced cancer. Support Care Cancer. 2013; 21(6):1709-16.

10. Dodd MJ, Cho, MH, Cooper BA, Miaskowski C. The effect of symptom clusters on functional status and quality of life in women with breast cancer. Eur J Oncol Nurs. 2010; 14(2):101-10.

11. Dialla PO, Chu W, Roignot P, Bone-Lepinoy MC, Poillot ML, Coutant C, et al. Impact of age-related socio-economic and clinical determinants of quality of life among long-term breast cancer survivors. Maturitas. 2015 ;81(3):362-70.

12. Ma C, Bandukwala S, Burman D, Bryson J, Seccareccia D, Banerjee S, et al. Intercorversion of three measures of performance status: an empirical analysis. Eur J Cancer. 2010; 46(18):3175-83.

13. Tomruk M, Faradibak D, Yavuzşen, Akman T. Predictors of functional capacity in colorectal cancer patients. Support Care Cancer. 2015; 23(9):2747-54.

14. Klinkhammer-Schalke M, Koller M, Steinger B, Ehret C, Ernst B, Wyatt JC, et al. Direct improvement of quality of life using a tailored quality of life diagnosis and therapy pathway: randomised trial in 200 women with breast cancer. Br J Cancer. 2012; 106(5):826-38.

15. Jette AM. Toward a common language for function, disability, and health. Phys Ther. 2006; 86(5):726-34.

16. Campbell KL, Pusic AL, Zucker DS, McNeely ML, Binkley JM, Cheville AL, et al. A prospective model of care for breast cancer rehabilitation: function. Cancer. 2012; 118(8 Suppl):2300-11.

17. World Health Organization (WHO). International Classification of Functioning, Disability and Health. Geneva: World Health Organization; 2001.

18. Gilchrist LS, Galantino ML, Wampler M, Marchese VG, Morris GS, Ness KK. A framework for assessment in oncology rehabilitation. Phys Ther. 2009; 89(3):286-306.

19. Péus D, Newcomb N, Hofer S. Appraisal of the Karnofsky Performance Status and proposal of a simple algorithmic system for its evaluation. BMC Med Inform Decis Mak. 2013; 13:72-9.

20. Johnson MJ, Bland JM, Davidson PM, Newton PJ, Oxberry SG, Abernethy AP, et al. The relationship between two performance scales: New York Heart Association Classification and Karnofsky Performance Status Scale. J. Pain Symptom Manag. 2014; 47(3):652-8.

21. Aaronson NK, Ahmedzai S, Bergman B, Bullinger M, Cull A, Duez NJ, et al. The European Organization for Research and Treatment of Cancer QLQ-C30: a quality-of life instrument for use in international clinical trials in oncology. J Natl Cancer Inst.1993; 85(5):365-76.

22. Vardar-Yagli N, Sener G, Saglam M, Calik-Kutukcu E, Arikan H, Inal-Ince $\mathrm{D}$, et al. Associations among physical activity, comorbidity, functional capacity, peripheral muscle strength and depression in breast cancer survivors. Asian Pac J Cancer Prev. 2015; 16(2):585-9.

23. Terret C, Albrand G, Moncenix G, Droz JP. Karnofsky Performance Scale (KPS) or Physical Performance Test (PPT)? That is the question. Crit Rev Oncol Hematol. 2011; 77(2):142-7.

24. Paiva CE, Siquelli FAF, Santos HA, Costa MM, Massaro DR, Lacerda DC, et al. The Functionality Assessment Flowchart (FAF): a new simple and reliable method to measure performance status with a high percentage of agreement between observers. BMC Cancer. 2015; 15:501.

25. Montazeri A, Vahdaninia M, Harirchi I, Ebrahimi M, Khaleghi F, Jarvandi S. Quality of life in patients with breast cancer before and after diagnosis: an eighteen months follow-up study. BMC Cancer. 2008; 8:330.

26. Zimmerman C, Burman D, Swami N, Krzyzanowska MK, Leighl N, Moore $\mathrm{M}$, Determinants of quality of life in patients with advanced cancer. Support Care Cancer. 2011; 19(5):621-9.

27. Efficace F, Therasse P, Piccart MJ, Coens C, van Steen K, Welnicka-Jaskiewicz $\mathrm{M}$, et al. Health-related quality of life parameters as prognostic factors in a nonmetastatic breast cancer population: An international multicenter study. J Clin Oncol. 2004; 22(16):3381-8.

28. Gotay CC, Kawamoto CT, Bottomley A, Efficace F. The prognostic significance of patient-reported outcomes in cancer clinical trials. J Clin Oncol. 2008; 26(8):1355-63. 
29. Thornton LM, Mandlensky L, Flatt SW, Kaplan RM, Pierce JP. The impact of a second breast cancer diagnosis on health related quality of life. Breast Cancer Res Treat. 2005; 92(1):25-33.

30. Alfano CM, Smith AW, Irwin ML, Bowen DJ, Sorensen B, Reeve BB, et al. Physical activity, long-term symptoms, and physical health-related quality of life among breast cancer survivors: a prospective analysis. J Cancer Surviv. 2007; 1(2):116-128

31. Mora S, Redberg RF, Cui Y, Whiteman MK, Flaws JA, Sharrett AR, et al. Ability of exercise testing to predict cardiovascular and all-cause death in asymptomatic women: a 20 -year follow-up of the lipid research clinics prevalence study. JAMA. 2003; 290(12):1600-7.

32. Gulati M, Black HR, Shaw LJ, Arnsdorf MF, Merz CN, Lauer MS, et al. The prognostic value of a nomogram for exercise capacity in women. $\mathrm{N}$ Engl J Med. 2005; 353(5):468-75.

33. Paraskevi T. Quality of life outcomes in patients with breast cancer. Oncol Rev. 2012; 6(1):e2. 